\title{
Lung Volume, Gas Mixing, and Mechanics of Breathing in Mechanically Ventilated Very Low Birth Weight Infants with Idiopathic Respiratory Distress Syndrome
}

\author{
K. E. EDBERG, K. SANDBERG, A. SILBERBERG, B. EKSTRÖM-JODAL, AND O. HJALMARSON \\ Department of Anesthesia and Intensive Care and Department of Pediatrics, Gothenburg University, and \\ Research Laboratory of Medical Electronics, Chalmers University of Technology, Gothenburg, Sweden
}

\begin{abstract}
We assessed pulmonary function in 14 mechanically ventilated newborn very low birth weight infants with idiopathic respiratory distress syndrome by means of a face-out, volume displacement body plethysmograph and nitrogen washout analyses. Specially designed computer programs were used for calculations of lung volumes, ventilation, gas mixing efficiency, and mechanical parameters. In addition to very low compliance and moderately elevated resistance of the respiratory system, there were considerably impaired gas mixing efficiency and low functional residual capacity (FRC). No correlations between positive end-expiratory pressure and mean airway pressure versus compliance, resistance, or FRC could be found. Neither could correlations be found between FRC and compliance or FRC and the calculated right to left shunt. (Pediatr Res 30: 496-500, 1991)
\end{abstract}

Abbreviations

$\mathrm{FiO}_{2}$, fraction of inspired oxygen

FRC, functional residual capacity

IRDS, idiopathic respiratory distress syndrome

MAP, mean airway pressure

NC, nitrogen clearance

$\mathrm{PaO}_{2}$, arterial oxygen tension

PIP, peak inspiratory pressure

For methodologic reasons, lung function studies in newborn infants with IRDS have largely been focused on lung mechanics. Using applied methods makes it possible to obtain a more comprehensive picture of ventilatory conditions, even in very premature, severely affected infants. To further clarify the pathophysiology of IRDS under conditions of mechanical ventilation in this group of infants, we assessed lung volume, alveolar ventilation, gas mixing efficiency, and lung mechanics in mechanically ventilated infants with birth weights below $1500 \mathrm{~g}$.

\section{MATERIALS AND METHODS}

We studied 14 very low birth weight infants with IRDS during intermittent positive pressure ventilation within $5 \mathrm{~d}$ (range $0-5$ d) of birth. Six of the infants were boys and eight were girls. Median birth weight was $1.29 \mathrm{~kg}$ (range $1.00-1.50 \mathrm{~kg}$ ) and

Received January 9, 1991; accepted April 24,1991.

Correspondence: Karl Erik Edberg, M.D., Department of Pediatric Anesthesia and Intensive Care, Children's Hospital, S-416 85 Gothenburg, Sweden.

Supported by Grants No. 5703 and 7543 from the Swedish Medical Research Council. median gestational age was 29 wk (range 26-33 wk). Informed consent was obtained from the parents of each infant before the procedure was carried out, and the study was approved by the ethics committee of Göteborg University.

Maternal history included preeclampsia in six cases and abruption of the placenta in three cases. One infant was a twin. Twelve infants were delivered by cesarean section. Apgar scores were below 5 at $1 \mathrm{~min}$ in seven infants and below 7 at $5 \mathrm{~min}$ in seven infants. All infants were flushed with oxygen immediately after birth, and nine were also ventilated using a mask. Ten of the infants with adequate spontaneous respiration were treated with continuous positive airway pressure by nasal prongs within $4 \mathrm{~h}$ of birth, and the other four were intubated and ventilated within a few minutes of birth. Mechanical ventilation was started within $27 \mathrm{~h}$ in all infants. The pulmonary disease was classified as IRDS in all infants (1). All initial radiographs showed a reticulogranular pattern, and no infant had positive blood cultures or hematologic signs of infection.

The following guidelines for mechanical ventilation of very low birth weight infants with IRDS were used in the intensive care unit: Nasal intubation with uncuffed endotracheal tubes 2.5-3.0 (Portex LTD, Hythe, Kent, UK) was performed. A Sechrist Infant Ventilator $400 \mathrm{~B}$ (Sechrist Industries Inc., Anaheim, CA) was connected to the endotracheal tube. The breathing gas was humidified and heated with a humidifier (Fisher and Paykel, Auckland, New Zealand). Initial ventilator settings were: respiratory rate 60 breaths/min, inspiratory/expiratory ratio $1 / 2$, PIP 25-30 $\mathrm{cm} \mathrm{H}_{2} \mathrm{O}$, PEEP 4-6 $\mathrm{cm} \mathrm{H}_{2} \mathrm{O}$, and $\mathrm{FiO}_{2}$ 0.5-1.0. With guidance from arterial blood gas analyses, PIP was then adjusted until normocapnia was achieved, and PEEP was increased until a distinct, sizeable rise in arterial oxygen tension was seen. $\mathrm{FiO}_{2}$ was then gradually reduced over several hours. The respiratory rate and the inspiratory/expiratory ratio were adjusted to improve ventilation or with the intention of eliminating spontaneous breathing.

The lung function studies were performed after initial adjustments of the ventilator treatment and when the infant was in a stable condition. Median time from start of artificial ventilation until the lung function study was performed was $15.5 \mathrm{~h}$ (range 1-93 h). At the time of study, median $\mathrm{FiO}_{2}$ was 0.50 (range $0.23-$ 0.85 ), respiratory rate 70 breaths/min (range 59-94 breaths/ $\mathrm{min}$ ), inspiratory time $0.37 \mathrm{~s}$ (range $0.21-0.52 \mathrm{~s}$ ), expiratory time 0.49 s (range $0.27-0.63 \mathrm{~s}$ ), PIP $25 \mathrm{~cm} \mathrm{H}_{2} \mathrm{O}$ (range $14-37 \mathrm{~cm}$ $\mathrm{H}_{2} \mathrm{O}$ ), PEEP $5.4 \mathrm{~cm} \mathrm{H}_{2} \mathrm{O}$ (range $3.8-9.9 \mathrm{~cm} \mathrm{H}_{2} \mathrm{O}$ ), and MAP was $14 \mathrm{~cm} \mathrm{H}_{2} \mathrm{O}$ (range 7.2-19 $\mathrm{cm} \mathrm{H}_{2} \mathrm{O}$ ).

Eleven infants were extubated within 1-8 d and later had normal outcomes. One infant developed bronchopulmonary dysplasia and had to be ventilated for several months. Two infants died, one at $2 \mathrm{~d}$ and the other at $1 \mathrm{mo}$, of severe respiratory insufficiency. 
We used a measuring system constructed to record respiratory flow continuously, as well as airway pressure and nitrogen concentration in breathing gas during mechanical ventilation and intensive care. This system has been described in detail elsewhere (2). Infants breathing vigorously against the ventilator were given a muscle relaxant (vecuronium bromide $0.1 \mathrm{mg} / \mathrm{kg}$ body weight) as a part of a clinical routine. Ventilatory flow was recorded by means of a face-out, volume displacement body plethysmograph placed inside the infant's incubator. A pneumotachograph (Fleisch no. 1; Siemens-Elema, Gothenburg, Sweden) was mounted in the wall of the plethysmograph and connected to a differential pressure transducer (ES EMT 32; Siemens-Elema). Airway pressure was measured in the proximal end of the endotracheal tube. Nitrogen washouts were performed and analyzed by means of a gas sampling device built into the endotracheal tube connector for nitrogen concentration measurement in a nitrogen analyzer (HP 47302A; Hewlett-Packard Co., Palo Alto, CA).

The mechanical parameters of the respiratory system were calculated by means of a least mean square analysis-based computer program (3). Work and work rate were calculated taking both resistive and elastic work into account (4). FRC, dead space, and alveolar ventilation were calculated according to Sjöqvist $e t$ al. (5). NC index, i.e. the amount of ventilation, normalized by the FRC, needed to wash out a nitrogen volume from 10 to $90 \%$ of its initial volume, expresses the gas mixing efficiency and was also calculated from the nitrogen elimination curve (6). The right to left shunt was calculated according to the alveolar-arterial oxygen tension gradient, using a nomogram (1).

Monitoring of the infants' vital functions was continued during the procedure. ECG, transcutaneous oxygen tension, and respiratory rate were continuously monitored in all infants. Arterial blood gases were analyzed before each measurement. The samples were drawn either from a radial or an umbilical arterial line. In some infants, arterial blood pressure was measured continuously. Rectal and skin temperature were also monitored.

\section{RESULTS}

In Table 1, mean values, $\mathrm{SD}$, and ranges of data from the nitrogen washout analyses are presented. FRC varied from 9.3 to $30 \mathrm{~mL}$ with a mean value of $20 \mathrm{~mL}$. Alveolar ventilation varied from 79 to $343 \mathrm{~mL} / \mathrm{min}$, with a mean value of $178 \mathrm{~mL} /$ min. NC varied from 4 to 19 with a mean value of 11 .

Mean values, $\mathrm{SD}$, and ranges of data on the mechanical parameters of the respiratory system are presented in Table 2. Compliance of the respiratory system varied from 0.25 to 0.52 $\mathrm{mL} / \mathrm{cm} \mathrm{H}_{2} \mathrm{O}$, with a mean value of $0.37 \mathrm{~mL} / \mathrm{cm} \mathrm{H}_{2} \mathrm{O}$. Resistance varied from 61 to $166 \mathrm{~cm} \mathrm{H} \mathrm{H}_{2} \mathrm{O} / \mathrm{L} / \mathrm{s}$ with a mean value of $95 \mathrm{~cm}$ $\mathrm{H}_{2} \mathrm{O} / \mathrm{L} / \mathrm{s}$.

Under the conditions of mechanical ventilation described, there were no evident correlations between compliance of the respiratory system, conductance, or calculated shunt and FRC (Fig. 1). Neither were there correlations between PEEP or birth weight and FRC (Fig. 2).

To test whether the duration of disease with ventilator treat-

Table 1. Mean values, $S D$, and ranges of data from nitrogen washout analyses*

\begin{tabular}{lcccc}
\hline Parameter & Mean & SD & Range & $\begin{array}{c}\text { Mean } / \mathrm{kg} \\
\text { body weight }\end{array}$ \\
\hline FRC $(\mathrm{mL})$ & 20 & 6.5 & $9.3-30$ & 15.5 \\
$\mathrm{~V}_{\mathrm{F}}(\mathrm{mL} / \mathrm{min})$ & 542 & 126 & $312-745$ & 424 \\
$\mathrm{~V}_{\text {A }}(\mathrm{mL} / \mathrm{min})$ & 178 & 73 & $79-343$ & 141 \\
$\mathrm{~V}_{\mathrm{T}}(\mathrm{mL})$ & 7.7 & 1.8 & $5-11$ & 6.1 \\
$\mathrm{~V}_{\mathrm{D}}(\mathrm{mL})$ & 5.2 & 1.2 & $3.2-6.5$ & 4.0 \\
$\mathrm{NC}$ & 11 & 3.8 & $4-19$ & \\
\hline
\end{tabular}

${ }^{*} \mathrm{~V}_{\mathrm{E}}$, total ventilation; $\mathrm{V}_{\mathrm{A}}$, alveolar ventilation; $\mathrm{V}_{\mathrm{T}}$, tidal volume; $\mathrm{V}_{\mathrm{D}}$, dead space.
Table 2. Mean values, $S D$, and ranges of data from analyses of mechanical parameters of respiratory system*

\begin{tabular}{lccc}
\hline \multicolumn{1}{c}{ Parameter } & Mean & SD & Range \\
\hline $\mathrm{Crs}\left(\mathrm{mL} / \mathrm{cm} \mathrm{H}_{2} \mathrm{O}\right)$ & 0.37 & 0.09 & $0.25-0.52$ \\
$\mathrm{Rrs}\left(\mathrm{cm} \mathrm{H} \mathrm{H}_{2} \mathrm{O} / \mathrm{L} / \mathrm{s}\right)$ & 95 & 31 & $61-166$ \\
$\mathrm{Crs} \cdot \mathrm{Rrs}(\mathrm{ms})$ & 36 & 14 & $17-68$ \\
$\mathrm{Crs} / \mathrm{FRC}\left(\mathrm{L} / \mathrm{cm} \mathrm{H}_{2} \mathrm{O}\right)$ & 0.021 & 0.011 & $0.011-0.053$ \\
$\mathrm{G} / \mathrm{FRC}\left[\mathrm{L} /\left(\mathrm{cm} \mathrm{H} \mathrm{H}_{2} \mathrm{O} \cdot \mathrm{s}\right)\right]$ & 0.65 & 0.33 & $0.22-1.4$ \\
Work $/$ breath $\left(\mathrm{cm} \mathrm{H} \mathrm{H}_{2} \mathrm{O} \cdot \mathrm{mL}\right)$ & 120 & 43 & $47-221$ \\
Work rate $(\mathrm{mW})$ & 15 & 5.6 & $4.7-24$ \\
Work $/ \mathrm{mL} \mathrm{V}_{7}\left(\mathrm{~cm} \mathrm{H} \mathrm{H}_{2} \mathrm{O}\right)$ & 17 & 3.6 & $9.5-34$ \\
\hline
\end{tabular}

* Crs, compliance of the respiratory system; Rrs, resistance of the respiratory system; $\mathrm{G}$, conductance; $\mathrm{V}_{\mathrm{T}}$, tidal volume.
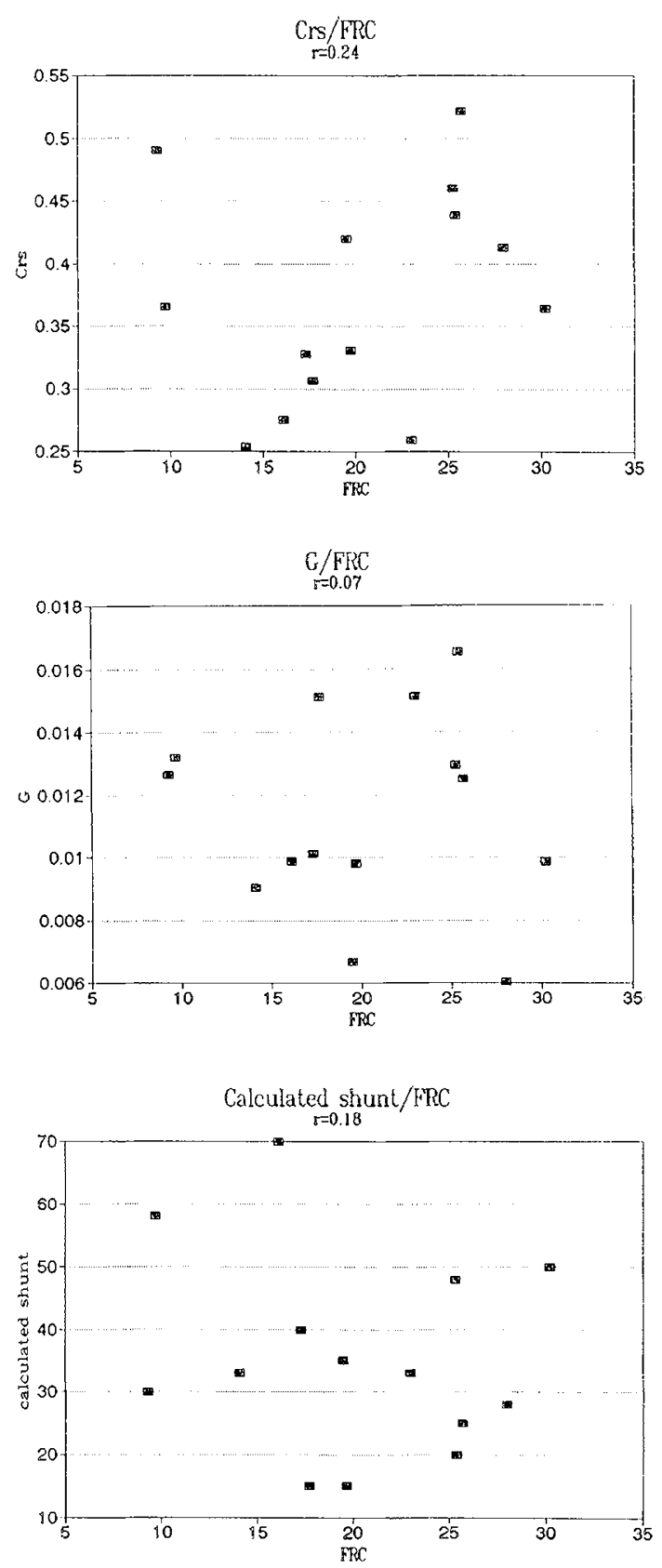

Fig. 1. Correlations between compliance of the respiratory system $(C r s)$, conductance $(G)$, calculated shunt, and FRC. 

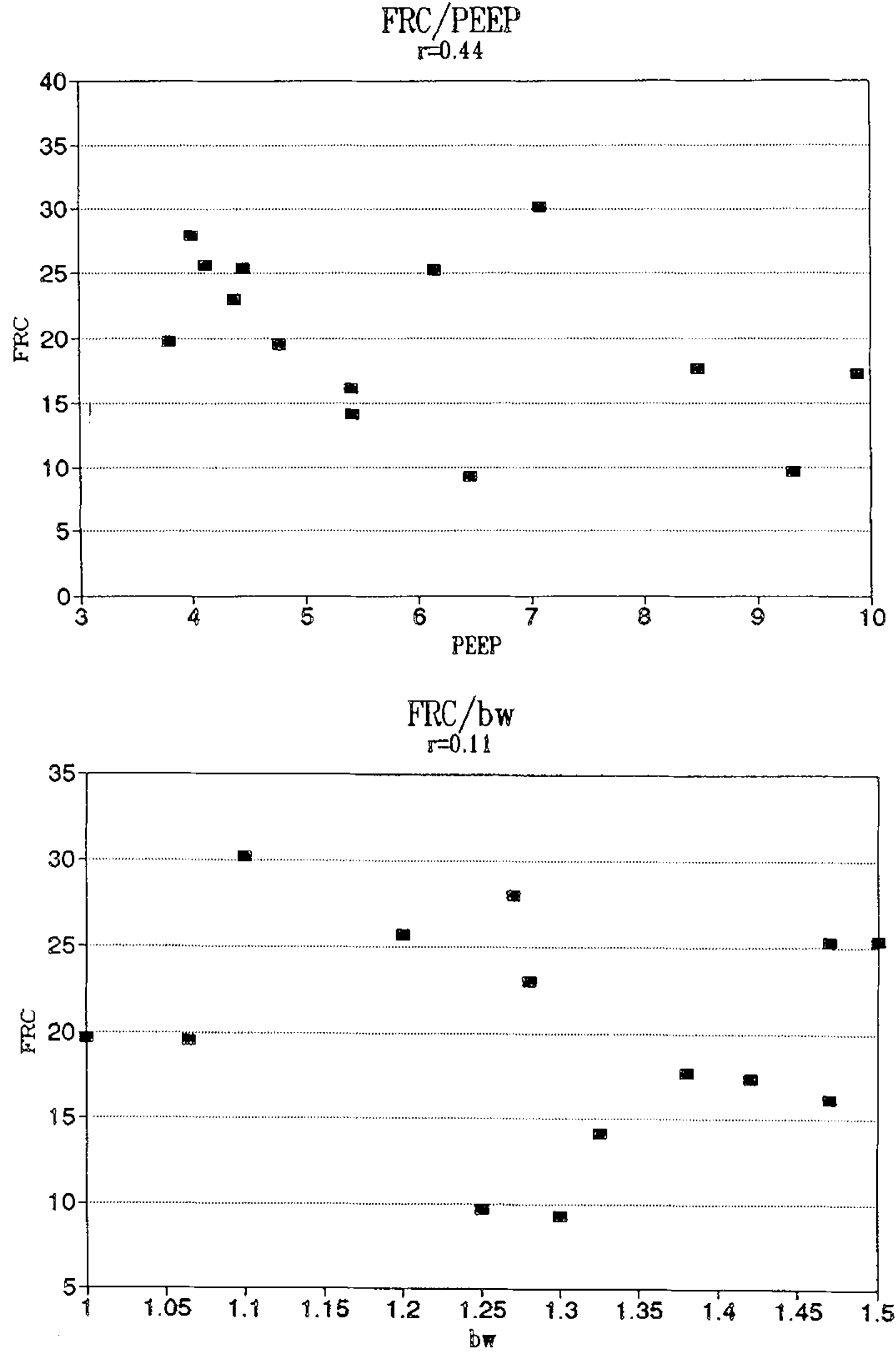

Fig. 2. Correlations between PEEP, body weight ( $b w)$, and FRC.

ment before the lung function study affected the results, the material was divided into two moieties according to time of ventilator treatment (above or below the median value of 15.5 h). Ventilatory index $\left[\left(\mathrm{FiO}_{2} \times \mathrm{MAP}\right) /\right.$ arterial oxygen tension $]$, $\mathrm{NC}$, and the calculated right to left shunt were higher in the infants investigated early during the course of the disease. No differences were seen in $\mathrm{FiO}_{2}, \mathrm{FRC}$, compliance, resistance, or MAP. Neither were there any differences in gestational age or birth weight between the two groups.

We also wanted to test whether the severity of disease, expressed as calculated right to left shunt, influenced any other calculated parameter at the time of study. Dividing the material at the median shunt value (33\%), we found no significant differences between the groups, except for a higher ventilatory index in the group with the larger shunt.

\section{DISCUSSION}

Assessment of pulmonary function in the sick, premature newborn infant needing intensive care has long been a challenge, not only because of the fragility of the newborns and their inability to cooperate, but also because of a limitation of available techniques. The use of whole body plethysmography in combination with a multiple breath nitrogen washout technique has several advantages. Air leaks around the endotracheal tube can be disregarded, because the ventilatory volume is recorded from the volume displacement of the chest movement. Extra dead space in a flowmeter in the artificial airway can be prevented. Mechanical ventilation does not have to be interrupted for measuring maneuvers, and both short and long studies can be performed, providing information on both mechanics of the respiratory system and simultaneous lung volumes.

One of the main findings of this study, in addition to generally low compliance and reduced FRC, was the greatly impaired capacity for efficient mixing of inspired and alveolar gas in lungs afflicted with IRDS. The mean value of NC in the ventilated infants with IRDS was 11 (SD 3.8), which can be compared with that of term healthy newborns, 5 (SD 0.4) (recalculated from Sandberg) (7). This reduced efficiency of gas mixing may be a result of a reduction of alveolar and small airway space in IRDS owing to disseminated atelectases and alveolar influx of fluid. Distended remaining air-filled structures and high ventilatory flow rates also contribute to the impaired gas mixing. Thus, gas mixing efficiency seems to be a characteristic feature of the pathophysiology of very preterm infants with IRDS.

The infants in the present study had very low respiratory system compliance, with a mean value of $0.37 \mathrm{~mL} / \mathrm{cm} \mathrm{H}_{2} \mathrm{O}$. This is in agreement with other findings (Tables 3 and 4) (8-19). Immaturity and poor development of alveolar tissue, lung surfactant deficiency, and increased leak of proteinaceous fluid into the alveolar space are probably contributing factors.

Airway resistance in spontaneously breathing, nongrunting infants with IRDS is hardly affected, or slightly elevated (20). Most studies on resistance of the respiratory system in mechanically ventilated infants with IRDS show increased values as compared with healthy preterms. The mean pulmonary resistance value of the infants in our study was $95 \mathrm{~cm} \mathrm{H}_{2} \mathrm{O} / \mathrm{L} / \mathrm{s}$, which was lower than values in other studies (Tables 3 and 4) (8-19). It is, however, difficult to make comparisons with data from

Table 3. Observations on mechanical parameters of lung and respiratory system*

\begin{tabular}{|c|c|c|c|}
\hline \multirow[b]{2}{*}{ Author } & \multicolumn{3}{|c|}{ Parameter } \\
\hline & $\begin{array}{l}\text { Crs } \\
(\mathrm{mL} / \mathrm{cm}\end{array}$ & $\begin{array}{r}\mathrm{Cl} \\
\left.\mathrm{H}_{2} \mathrm{O}\right) \\
\end{array}$ & $\begin{array}{lr}\text { Rrs } & \mathrm{Rl} \\
\left(\mathrm{cm} \mathrm{H} \mathrm{H}_{2} \mathrm{O} / \mathrm{L} / \mathrm{s}\right) \\
\end{array}$ \\
\hline Philips et al. (8) & $\begin{array}{l}0.60 \dagger \\
0.46 \dagger \\
0.35 \dagger\end{array}$ & & \\
\hline $\begin{array}{l}\text { Thomson and } \\
\text { Silverman (9) }\end{array}$ & $0.21-0.71$ & & $120-380$ \\
\hline $\begin{array}{l}\text { Bhutani et al. } \\
\text { (10) }\end{array}$ & & 0.44 & 106 \\
\hline $\begin{array}{l}\text { Bhutani et al. } \\
\text { (11) }\end{array}$ & & $0.30-0.43$ & 116 \\
\hline Davis et al. (12) & & 0.38 & 64 \\
\hline $\begin{array}{l}\text { Couser et al. } \\
\text { (13) }\end{array}$ & & $0.33-0.43$ & $141-160$ \\
\hline $\begin{array}{l}\text { Goldman et al. } \\
\text { (14) }\end{array}$ & & $0.48-0.56$ & $85-150$ \\
\hline
\end{tabular}

(14)

*Crs, compliance of the respiratory system; $\mathrm{Cl}$, compliance of the lung; Rrs, resistance of the respiratory system; $\mathrm{Rl}$, resistance of the lung. $\dagger$ Values for different levels of PEEP; 0, 5 , and $10 \mathrm{~cm} \mathrm{H}_{2} \mathrm{O}$

$\ddagger$ Different technique for respiratory flow measurement.

Table 4. Observations on mechanical parameters of respiratory system*

\begin{tabular}{|c|c|c|}
\hline \multirow[b]{2}{*}{ Author } & \multicolumn{2}{|c|}{ Parameter } \\
\hline & $\begin{array}{c}\mathrm{Crs} \\
\left(\mathrm{mL} / \mathrm{cm} \mathrm{H} \mathrm{H}_{2} \mathrm{O}\right)\end{array}$ & $\begin{array}{c}\text { Rrs } \\
\left(\mathrm{cm} \mathrm{H} \mathrm{H}_{2} \mathrm{O} / \mathrm{L} / \mathrm{s}\right)\end{array}$ \\
\hline LeSouef et al. (15) & 0.76 & 124 \\
\hline Simbruner et al. (16) & $0.51-0.60$ & \\
\hline Popow and Simbruner (17) & 0.58 & \\
\hline Dreizzen et al. (18) & 0.53 & \\
\hline Prendiville et al. (19) & 0.61 & $195-224$ \\
\hline
\end{tabular}

* Crs, compliance of the respiratory system; Rrs, resistance of the respiratory system. 
nonintubated spontaneously breathing infants and mechanically ventilated infants as well as with different materials of mechanically ventilated infants for several reasons. One contributing factor to the raised flow resistance is the endotracheal tube (21). The tube size and the type of connector is of major importance, as is the size of air flow that is forced through by the mechanical ventilator (22). Kinking of the tube, improper position, and tracheal secretions are other factors that might affect endotracheal tube resistance and possibly also explain the very wide range of values seen in most investigations.

The time constant is a variable of great importance to adjustments of the ventilator settings. Too high a time constant might give rise to a risk of air trapping and inadvertent PEEP (16). In our infants, time constants varied from 17 to $68 \mathrm{~ms}$ with a mean value of $36 \mathrm{~ms}$. Considering the highest time constant among our infants, a $50 \%$ increase of resistance would mean a risk of air trapping at a ventilatory rate of 60 breaths/min and an inspiratory/expiratory ratio of $1 / 1$.

Only a limited amount of data is available on measurements of FRC in preterm newborns with IRDS. Richardson et al. (23) presented data on 32 intubated, spontaneously breathing newborn preterms on continuous positive airway pressure with a mean body weight of $2.013 \mathrm{~kg}$ and a mean FRC of $21.4 \mathrm{~mL}$, using a nitrogen washout technique. They have also presented later work on a similar material with intermittent positive pressure ventilation, using the same technique, with a FRC of 14.5 $\mathrm{mL} / \mathrm{kg}$ body weight (24). Heaf et al. (25) measured FRC with a closed-circuit helium dilution technique in nine mechanically ventilated preterm infants with IRDS and found FRC to vary between 13.3 and $18.1 \mathrm{~mL} / \mathrm{kg}$ body weight during the first $48 \mathrm{~h}$ of life. Bose et al. (26) described a multiple gas rebreathing technique with which they found a mean FRC of $10.8 \mathrm{~mL} / \mathrm{kg}$ body weight in 10 mechanically ventilated preterm newborns. Our data are in good agreement with data from two of these investigators, although our values were slightly higher than those of Bose et al. and those in the first work of Richardson et al. Differences in mode of ventilation may have contributed to these discrepancies $(23,26)$. We can consequently confirm the observations that infants with IRDS and a demand for respiratory support have lower FRC than comparable groups without lung disease (27-30).

As shown in Figure 2, there was no correlation between PEEP level and FRC. Bose et al. (26) showed that a change in PEEP level is strongly correlated with a change in FRC. In our group of infants, however, effects of changes in ventilator settings in the individual infant were not included in the measurements, and the combined impact of the pulmonary disease rather than PEEP or any other single variable seemed to be the determinant of the lung volume. Thus, we found no correlation between compliance or conductance and FRC as a possible effect of distension and overdistension of airways and alveoli (Fig. 1).

Work rate of breathing was considerably higher in our mechanically ventilated preterm infants than in spontaneously breathing infants of comparable sizes with IRDS and with the same total ventilation (4). This was mainly attributable to the much lower compliance in the ventilated infants. This increased work rate can be considered a measure of the increased net effect the respiratory muscles would have to develop to overcome the respiratory insufficiency. The evident failure of the respiratory muscles to do this is, however, probably a consequence of poor muscular effect due to the soft thoracic walls.

The impact of ventilator treatment time and duration of disease was studied by dividing the material in two moieties according to duration of the ventilator treatment. The higher ventilatory index, calculated right to left shunt, and NC index found in infants investigated early during the course of the disease indicate that these infants had a more severe pulmonary disease. Inasmuch as the majority of the infants improved and were extubated within $8 \mathrm{~d}$ and because infants with IRDS usually start to improve clinically after $2-3 \mathrm{~d}$, this difference is not surprising.
We were not able to sort out any specific entity in the pulmonary function tests that indicated the development of chronic lung disease, nor was any particular variable attributed to a longer duration of ventilator treatment. Neither was any mechanical or ventilatory variable strongly correlated to the calculated right to left shunt.

The observation by Richardson et al. (24) that there was a linear correlation between alveolar-arterial oxygen gradients and FRC could not be confirmed in our study. Extrapulmonary shunting or pulmonary ventilation-perfusion mismatch may contribute to this difference in data.

In conclusion, very immature infants with severe IRDS requiring mechanical ventilation have considerably impaired gas mixing efficiency in addition to low FRC, very low compliance, and moderately elevated resistance of the respiratory system. The results of the measurements of FRC, compliance, and resistance are similar to values measured by other techniques in similar populations of infants. FRC varied considerably without evident correlation to PEEP or any other parameter of the ventilator settings. To maintain normal blood gases, ventilation had to be elevated, and the work rate required to ventilate the sick lungs was considerably higher than in spontaneously breathing infants. Within the group, there were no correlations between FRC, mechanical parameters, or severity of disease expressed as calculated right to left shunt. Neither did differences in duration of ventilator treatment affect any mechanical parameters.

\section{REFERENCES}

1. Hjalmarson O 1981 Epidemiology and classification of acute neonatal respiratory disorders. A prospective study. Acta Paediatr Scand 70:773-783

2. Edberg KE, Sandberg K, Silberberg A, Sjöqvist BA, Ekström-Jodal B, Hjalmarson O 1991 A plethysmographic method for assessment of lung function in mechanically ventilated very low birth weight infants. Pediatr Res 30:501504

3. Uhl RR, Lewis FJ 1974 Digital computer calculation of human pulmonary mechanics using a least square fit technique. Comput Biomed Res 7:489495

4. Hjalmarson O, Olsson T 1974 Mechanics of breathing in newborn infants with pulmonary disease. IV. Work of breathing. Acta Paediatr Scand [Suppl] 247:49 60

5. Sjöqvist BA, Sandberg K, Hjalmarson O, Olsson T 1986 Method for analyzing multiple breath nitrogen washouts. Med Biol Eng Comput 24:83-90

6. Sandberg K, Sjöqvist BA, Hjalmarson O, Olsson T 1984 Analysis of alveolar ventilation in the newborn. Arch Dis Child 59:542-547

7. Sandberg K, Sjöqvist BA, Hjalmarson O, Olsson T 1986 Effects of delivery by caesarian section on lung function in healthy newborn infants. Acta Paediatr Scand 75:470-476

8. Philips JB, Beale EF, Howard JE, Jaeger MJ, Eitzman DV 1980 Effect of positive end-expiratory pressure on dynamic respiratory compliance in neonates. Biol Neonate 38:270-275

9. Thomson A, Silverman M 1985 Single-breath measurement of lung mechanics in very low birth weight infants. Crit Care Med 1:4-8

10. Bhutani VK, Sivieri EM, Abbasi S, Schaffer TH 1988 Evaluation of neonatal pulmonary mechanics and energetics: a two factor least mean square analysis. Pediatr Pulmonol 4:150-158

11. Bhutani VK, Abbasi S, Sivieri EM 1988 Continuous skeletal muscle paralysis: effect on neonatal pulmonary mechanics. Pediatrics 81:419-422

12. David JM, Veness-Meehan K, Notter RH, Bhuthani VK, Kendig JW, Shapiro DL 1988 Changes in pulmonary mechanics after the administration of surfactant to infants with respiratory distress syndrome. N Engl J Med 319:476-479

13. Couser RJ, Ferrara TB, Ebert J, Hoekstra RE, Fangman JJ 1990 Effects of exogenous surfactant therapy on dynamic compliance during mechanical breathing in preterm infants with hyaline membrane disease. $J$ Pediatr 116:119-124

14. Goldman SL, Gerhardt $T$, Sonni R, Feller R, Hehre D, Tapia JL, Bancalari E 1983 Early prediction of chronic lung disease by pulmonary function testing. J Pediatr 102;613-617

15. Lesouef PN, England SJ, Bryan AC 1984 Passive respiratory mechanics in newborns and children. Am Rev Respir Dis 129:552-556

16. Simbruner G 1986 Inadvertent positive end-expiratory pressure in mechanically ventilated newborn infants: detection and effect on lung mechanics and gas exchange. J Pediatr 108:589-595

17. Popow C, Simbruner G 1989 Influence of tidal volume on the compliance of the respiratory system in mechanically ventilated newborn infants. Wien Klin Wochenschr 9:323-326

18. Dreizzen E, Migdal M, Praud JP, Saby MA, Chambille B, Dehan M, Gaultier C 1989 Passive total respiratory system compliance and gas exchange in newborns with hyaline membrane disease. Pediatr Pulmonol 6:2-7

19. Prendiville A, Thomson A, Silverman M 1986 Effect of tracheobronchial 
suction on respiratory resistance in intubated preterm babies. Arch Dis Child $61: 1178-1183$

20. Hjalmarson O 1974 Mechanics of breathing in newborn infants with pulmonary disease. III. Mechanical and ventilatory parameters in healthy and diseased newborn infants. Acta Paediatr Scand [Suppl] 247:26-48

21. LeSouef PN, England SJ, Bryan AC 1984 Total resistance of the respiratory system in preterm infants with and without an endotracheal tube. J Pediat 104:108-111

22. Hatch DJ 1978 Tracheal tubes and connectors used in neonates-dimensions and resistance to breathing. Br J Anaesth 50:959-964

23. Richardson P, Wyman M, Jung AL 1980 A method of estimating the functional residual capacity of infants with respiratory distress syndrome. Crit Care Med 11:667-670

24. Richardson P, Bose CL, Carlstrom JR 1986 The functional residual capacity in infants with respiratory distress syndrome. Acta Paediatr Scand 75:267271
25. Heaf DP, Belik J, Spitzer AR, Gewitz MH, Fox WW 1982 Changes in pulmonary function during the diuretic phase of respiratory distress syndrome. J Pediatr 101:103-107

26. Bose CL, Lawson EE, Greene A, Mentz W, Friedman M 1986 Measuremen of cardiopulmonary function in ventilated neonates with respiratory distress syndrome using rebreathing methodology. Pediatr Res 20:316-320

27. Berglund $G$, Karlberg P 1956 Determination of the functional residual capacity in newborn infants. Acta Paediatr Scand 45:541-544

28. Lacourt G, Polgar G 1974 Development of pulmonary function in late gestation. I. The functional residual capacity of the lung in premature children. Acta Paediatr Scand 63:81-88

29. Ronchetti R, Stocks J, Keith I, Godfrey B 1975 An analysis of a rebreathing method for measuring lung volume in the premature infant. Pediatr Res 9:797-802

30. Moriette G, Chaussin M. Radvanyi-Bouvet M-F, Walti H, Pajot N, Relier J-P 1983 Functional residual capacity and sleep states in the premature newborn. Biol Neonate 43:125-133 